\title{
MONITORING DAN EVALUASI LOKASI PENYELAMAN PULAU BUNAKEN TAMAN NASIONAL BUNAKEN KOTA MANADO PROVINSI SULAWESI UTARA
}

\author{
Alfret Luasunaung, Victoria Manoppo, Joshian N.W. Schaduw \\ Dosen Fakultas Perikanan dan IImu Kelautan, Universitas Sam Ratulangi, Manado \\ Email : nicolas_schaduw@yahoo.com
}

\begin{abstract}
ABSTRAK
Penelitian ini bertujuan untuk menganalisis status ekologi daerah penyelaman (dive spot) serta merumuskan strategi yang cocok untuk pengelolaan dan upaya pelestarian terumbu karang, ikan karang dan biota laut secara berkelanjutan pada kawasan penyelaman di perairan Pulau Bunaken. Metode yang digunakan adalah teknik LIT (Line Intercept Transect), dan menganalisis persentase total tutupan karang menggunakan formulasi Gomez and Yap (1978). Hasil [penelitian menunjukkan bahwa secara umum kondisi lokasi penyelaman di Pulau Bunaken masih dalam kategori baik, akan tetapi terdapat indikator menurunnya kualitas terumbu karang dari tahun ke tahun, serta meningkatnya sampah yang masuk ke perairan Pulau Bunaken.
\end{abstract}

\section{Kata kunci : Evaluasi; Monitoring; Terumbu Karang; Bunaken}

PENDAHULUAN
Seiring dengan berjalannya
pembangunan dan dengan semakin
dikenalnya indonesia sebagai salah satu
daerah tujuan wisata maka pemanfaatan
sumberdaya alam sebagai objek daya tarik
wisata semakin sering dilakukan.
Pemanfaatan in seringkali tidak
memperhatikan kelestarian dari sumberdaya
atau objek daya tarik wisata tersebut
sehingga mengakibatkan kerusakan pada
objek wisata tersebut. Kerusakan yang
disebabkan karena pemanfaatan yang
berlebihan dan tidak memperhatikan
kelestarian ini akan membuat objek wisata
tersebut menjadi rusak atau tidak
berkelanjutan dan menjadi tidak menarik lagi
untuk dikunjungi.
Pembangunan kepariwisataan ditujukan
untuk memberikan manfaat kepada
pemenuhan kebutuhan masyarakat dan
peningkatan kualitas hidup dan
kesejahteraan masyarakat. Tujuan ini
sangat luhur dan positif, namun
kenyataannya seringkali muncul berbagai
permasalahan teknis meskipun sepertinya
perencanaan yang dibuat telah dianggap
sempurna (Marpaung, 2002). perencanaan
Pembangunan dan akan
pariwisata yang berkelanjutan akan

meningkatkan kualitas hidup dan mendorong perkembangan ekonomi masyarakat serta melestarikan sumberdaya yang ada. Pariwisata terutama wisata alam merupakan salah satu sektor yang mengalami pertumbuhan yang sangat pesat pada saat ini. Wisata alam telah memberikan kontribusi yang besar dalam pembangunan negara kita. Salah satu wisata alam yang mempunyai prospek yang sangat baik terutama di Indonesia bagian timur adalah wisata selam. Wisata selam telah menjadi andalan Sulawesi Utara dalam sektor pariwisata sejak Pulau Bunaken diperkenalkan pada dunia internasional.

Sebelum ditemukannya taman laut di Raja Ampat, Wakatobi dan Pulau Komodo, Pulau Bunaken telah dikenal oleh dunia internasional sebagai salah satu destinasi wisata selam dengan keindahan terumbu karang dan keanekaragaman biota lautnya. Seiring dengan ditetapkannya Taman Laut Bunaken sebagai Taman Nasional Bunaken, mulai muncul permasalahan-permasalahan baik masalah lingkungan maupun konflik dalam pengelolaan.

Melihat urgensi dari hal yang diuraikan tadi maka tujuan penelitian ini adalah menganalisis status ekologi daerah penyelaman (dive spot) yang berada di Pulau

MONITORING DAN EVALUASI LOKASI PENYELAMAN PULAU BUNAKEN 
Bunaken serta merumuskan strategi yang cocok untuk pengelolaan berkelanjutan daerah penyelaman (dive spot) yang berada di Pulau Bunaken sedangkan manfaat dari penelitian ini adalah melestarikan sumberdaya alamseperti terumbu karang, ikan karang dan biota laut lainnya pada daerah penyelaman di Pulau Bunaken agar kegiatan pariwisata bisa berkelanjutan.

\section{METODOLOGI PENELITIAN}

Data yang hendak dikumpulkan untuk penelitian ini terdiri atas data primer dan sekunder. Data primer dikumpulkan atau diperoleh langsung dari lokasi penelitian, melalui kuesioner, wawancara, observasi serta pengukuran langsung di lapangan.

Survei sampling artinya kegiatan survei yang menggunakan sampling, yaitu tidak semua unit analisis dalam populasi diamati satu per satu, akan tetapi hanya sebagian saja, yang diwakili oleh sampel. Proses pengambilan sampel disebut juga teknik sampling. Ukuran sampel bisa beragam karena bergantung kepada faktor dan pertimbangan; baik secara teknik maupun statistik. Pengumpulan data primer meliputi data biofisik dan sosial ekonomi yang dilakukan secara langsung di lapangan (observasi).

Pengambilan data potensi ekosistem terumbu karang dilakukan dengan teknik LIT atau Line Intercept Transect (UNEP, 1993), dengan ukuran transek $50 \mathrm{~m}$. Setiap biota yang dilewati transek dicatat menurut kategorinya. Dari data tersebut akan diketahui persentase tutupan, keragaman jenis dan dominasi karang batu. Setiap stasiun ditentukan titik-titik pengambilan data sesuai hasil survei. Setiap titik dibagi dalam 2 kedalaman yaitu $3 \mathrm{~m}$ dan $10 \mathrm{~m}$

Untuk pengambilan data ikan karang yang terdiri dari spesies indikator (Chaetodontidae) dan spesies mayor menggunakan metode Sensus Visual (Halford dan Thompson, 1994). Parameter yang diukur adalah keragaman spesies (jumlah spesies tiap lokasi), kepadatan (jumlah individu tiap lokasi), indeks keanekaragaman. Penetapan areal penelitian mengikuti lokasi pengambilan data karang batu.

\section{Analisis Ekologi Terumbu Karang}

Untuk menganalisis keanekaragaman jenis (genus) karang batu dan ikan karang digunakan formulasi Shannon-Wiener (Hill,1973). Selain itu akan dilakukan juga perhitungan nilai kerapatan, kerapatan relatif, dominasi, dominasi relatif, frekuensi relatif dan nilai penting.

Analisis persentase total tutupan karang akan menggunakan formulasi Gomez and Yap (1978), sedangkan untuk menghitung kepadatan relatif setiap jenis diperoleh melalui rumus:

$$
\text { Kepadatan relatif }=\frac{\text { Total inviduper genus }}{\text { Total individu seluruh genus }} \times 100
$$

Penentuan kondisi terumbu karang di Pulau Bunaken dengan mengacu pada Keputusan Menteri Negara Lingkungan Hidup: KEP - 04/MENLH/02/2001 Tentang Kriteria Baku Kerusakan Terumbu Karang.

\section{HASIL DAN PEMBAHASAN}

Pulau Bunaken memiliki karang dengan rata-rata masuk dalam kategori "baik". Dalam melakukan analisis Pulau Bunaken dibagi menjadi 10 wilayah analisis. Wilayah analisis bunaken 1 secara umum masuk dalam kategori "sangat baik", dan di dalam wilayah analisis tersebut terdapat satu titik penyelaman yaitu Mike's. Pada titik penyelaman tersebut kondisi karang masuk dalam kategori "sedang".

Wilayah analisis bunaken 2 secara umum kondisi karang masuk dalam kategori "sangat baik", dan di dalam wilayah analisis tersebut terdapat dua titik penyelaman yaitu Raymond's dan Mandolin. Kondisi karang pada dua titik penyelaman tersebut masuk dalam kategori "baik". Wilayah analisis bunaken 3 secara umum memiliki kondisi karang dalam kategori "baik", dan dalam 
wilayah analisis tersebut terdapat dua titik penyelaman yaitu Tengah dan Fukui. Kedua titik penyelaman tersebut memiliki karang dengan kategori "jelek", dimana pada dua titik penyelaman tersebut pada umumnya dikunjungi oleh penyelam pemula atau untuk belajar menyelam. Hal ini terjadi karena pada dua titik penyelaman tersebut memiliki arus yang tidak kencang, dan rata sehingga sangat memungkinkan untuk kelas pemula.

Wilayah analisis bunaken 4 secara umum masuk dalam kategori "jelek", sedangkan wilayah analisis bunaken 5 secara umum masuk dalam kategori "sedang". Wilayah analisis bunaken 5 terdapat satu titik penyelaman yaitu Alung Banua, dengan kondisi karang pada titik penyelaman tersebut masuk dalam kategori "jelek". Hal ini disebabkan karena pada titik penyelaman tersebut aktifitas wisata yang banyak dilakukan adalah snorkeling, sehingga banyak karang yang patah akibat terinjak.

Wilayah analisis bunaken 6 secara umum masuk dalam kategori "baik", sedangkan wilayah analisis bunaken 7 secara umum masuk dalam kategori "sedang". Wilayah analisis bunaken 6 terdapat satu titik penyelaman yaitu Tawara, dengan kondisi karang pada titik penyelaman tersebut masuk dalam kategori "jelek". Kegiatan pariwisata yang banyak dilakukan pada titik penyelaman tersebut adalah snorkeling, sehingga banyak karang yang patah akibat terinjak.

Wilayah analisis bunaken 8 secara umum masuk dalam kategori "sangat baik", dengan titik penyelaman yang terdapat pada wilayah tersebut adalah Celah-celah, Lekuan 1, Lekuan 2 dan Lekuan 3. Kondisi karang pada titik penyelaman Celah-celah yaitu masuk dalam kategori "sangat baik", sedangkan pada titik penyelaman Lekuan 1, Lekuan 2, dan Lekuan 3 masuk dalam kategori "baik". Kegiatan pariwisata yang banyak dilakukan pada wilayah tersebut adalah menyelam, dan jalur katamaran dari titik penyelaman Lekuan 1 sampai titik penyelaman Muka Kampung (wilayah analisis bunaken 9 ).

Wilayah analisis bunaken 9 secara umum masuk dalam kategori "baik" dengan titik penyelaman yang terdapat di dalam wilayah tersebut adalah Muka Kampung dan Tanjung Paser. Kondisi karang pada titik penyelaman Muka Kampung masuk dalam kategori "baik", sedangkan pada titik penyelaman Tanjung Paser masuk dalam kategori "sangat baik". Kegiatan pariwisata yang banyak dilakukan pada wilayah tersebut adalah menyelam dan katamaran.

Wilayah analisis bunaken 10 secara umum masuk dalam kategori "sangat baik", dengan titik penyelaman yang terdapat di wilayah tersebut adalah Timur, Pangalisang dan Sachiko. Pada titik penyelaman Timur memiliki karang dalam kategori "sangat baik", titik penyelaman Pangalisang masuk dalam kategori "baik", sedangkan pada titik penyelaman Sachiko masuk dalam kategori "jelek". Kegiatan pariwisata yang banyak dilakukan pada titik penyelaman tersebut adalah menyelam.

Penelitian ini juga menghasilkan bahwa jumlah titik penyelaman yang ada di Pulau Bunaken adalah sebanyak 16 titik penyelaman. Masing-masing titik penyelaman memiliki daya tarik wisata, seperti pada titik penyelaman Lekuan 1, Lekuan 2 dan Lekuan 3 dimana daya tarik utama pada titik penyelaman di wilayah tersebut karena memiliki tubir vertical, patahan dan lembah, terlindung dari gelombang/ombak, namun pada titik penyelaman Lekuan 2 sering ada arus kuat, dan terkadang arus bergerak ke bawah. Kehidupan bawah air yang terdapat pada titik penyelaman Lekuan 1 berupa berbagai kelompok besar ikan pemakan plankton: fusiliers, pyramid butterfly fishes, banner fishes, dan dam selfishes, serta avertebrata berupa giant barrel sponges, black coral, lilin dan kipas laut/bulu ayam. Peluang temuan menarik adalah penyu hijau, hiu ekor hitam, ular laut, kerapu, ikan emperor besar, ikan kakak tua (tandukuhang), napoleon (maming), dan bobara. 
Titik penyelaman Lekuan 2 kehidupan bawah air berupa penyu hijau, hiu ekor hitam, ular laut, kerapu, ikan emperor besar, ikan kakak tua (tandukuhang), napoleon (maming), dan bobara. Peluang menarik yang bisa dijumpai adalah berupa ular laut, hiu ekor putih, pari burung, ikan kakatua besar, gerombolan bobara, dan ikan maming (napoleon). Selanjutnya pada titik penyelaman Lekuan 3 karakteristik bawah air berupa ikan: ular laut, hiu ekor putih, pari, burung, ikan kakatua, besar, gerombolan bobara, dan ikan maming (napoleon). Peluang temuan menarik berupa bara kuda, napoleon, penyu, dan pari papan.

Titik penyelaman Celah Celah dan Alung Banua daya tarik utama adalah penyelaman di malam hari. Karakteristik bawah air berupa tubir vertical dengan banyak patahan dan hancuran karang, sangat terlindung dari gelombang dan arus, dan khusus pada titik penyelaman Alung Banua terdapat beberapa goa kecil. Kehidupan bawah air pada titik penyelaman Celah-celah berupa ikan: ikan kupu-kupu, ikan kakak tua, dan ikan dokter (kulit pasir), serta invertebrates berupa berbagai jenis karang batu, karang hitam, gorgonians, ascidians dan lili laut. Selanjutnya pada titik penyelaman Alung Banua kehidupan bawah air berupa berbagai ikan terumbu: anthiases, ikan kakak tua, kupukupu, dan ikan keling, ikan gobi udang, lepu ayam, dan gerombolan besar gorara hitam serta avertebrata berupa: nudibrancia, karang lunak, spons, ascidians, dan berbagai bentuk karang batu. Peluang temuan menarik yang bisa dijumpai adalah berupa baracuda, napoleon besar, penyu sisik, penyu hijau dan pari papan.

Titik penyelaman Fukui memiliki karakteristik bawah air berupa lereng yang keseluruhannya dipenuhi oleh karang daun dan karang bercabang. Kehidupan bawah air berupa banyak gerombolan ikan: spade fishes, gorara hitam, barakuda sirip hitam, bobara, raja bao, ikan pelatuk besar, dan belut pasir/belut taman, serta invertebrates berupa spons tabung raksasa, dan kima raksasa. Peluang menarik yang dapat dijumpai adalah berupa barakuda besar, sweet lips besar, ikan napoleon, ikan kakaktua beasr, pari burung, mola mola, hiu kecil dan pari papan dan yang paling langka dan menarik dijumpai adalah perkawinan ikan keling cahaya, dan paracheilinus filamentous.

Titik penyelaman Mandolin memiliki karakteristik tubir karang vertical, dengan gua-gua kecil pada bagian yang lebih dalam, terumbu bagian atas sangat menarik dan beragam, dan sering ada arus yang kuat. Kehidupan bawah air berupa banyak gerombolan ikan pemakan plankton: lolosi, ikan kupu-kupu, damselfish, dan ikan peri besar, juga banyak terdapat ikan gobi merah. Avertebrata yang terdapat didalamnya berupa: karang hitam, gorgonia besar, dan ascidia. Peluang menarik yang dapat dijumpai berupa Green and Hawksbill turtles, sea snakes, white tip reef sharks, school of big eye tree valleys, barracudas, dogtooth tunas, eagle rays, sting rays, giant sweet lips, groupers and Napoleon wrasses.

Titik penyelaman Raymond's karakteristik bawah air berupa tubir vertical, dengan satu gua besar, terumbu bagian atas yang menarik, namun sangat rentan dengan kondisi alam karena terletak pada arah angin yang dapat menimbulkan badai. Kehidupan bawah air berupa ikan, dan mungkin merupakan lokasi paling kaya dalam keragaman ikan seperti: ikan peri, ikan kupukupu, ikan keling dan lain-lain, serta memiliki avertebrata berupa banyak lobster, hutan karang dan berbagai jenis karang batu dan karang lunak. Peluang menarik yang dapat dijumpai berupa seasnakes, large emperors, red snappers, groupers, dogtooth tuna, eagle rays and stingrays.

Titik penyelaman Mike's karakteristik bawah air berupa tubir vertical berbentuk amfiiheater, serta puncak terumbu terbuka terhadap ombak. Kehidupan bawah air berupa banyak anthias, ikan peri, tilefishes, dan memiliki avertebrata berupa bongkahan karang besar-besar, karang hitam, gorgonia raksasa, dan ascidia. Peluang menarik yang dapat dijumpai berupa white tip sharks, giant 
trivially, eagle rays, and occasionally very large, silvertip sharks.

Titik penyelaman Timur memiliki karakteristik bawah air berupa tubir vertical, dengan banyak celah dan gua kecil dan sangat menarik untuk kegiatan wisata snorkling. Memiliki kehidupan bawah air berupa ikan kupu-kupu, ikan dokter, ikan kakaktua, dan ikan keling/maming, dan avertebrata berupa banyak karang lunak (Nephthiidae), karang hitam, gorgonia, dan ascidia. Peluang menarik yang dapat dijumpai berupa Penyu, Hiu Ekor Putih, dan Pari.
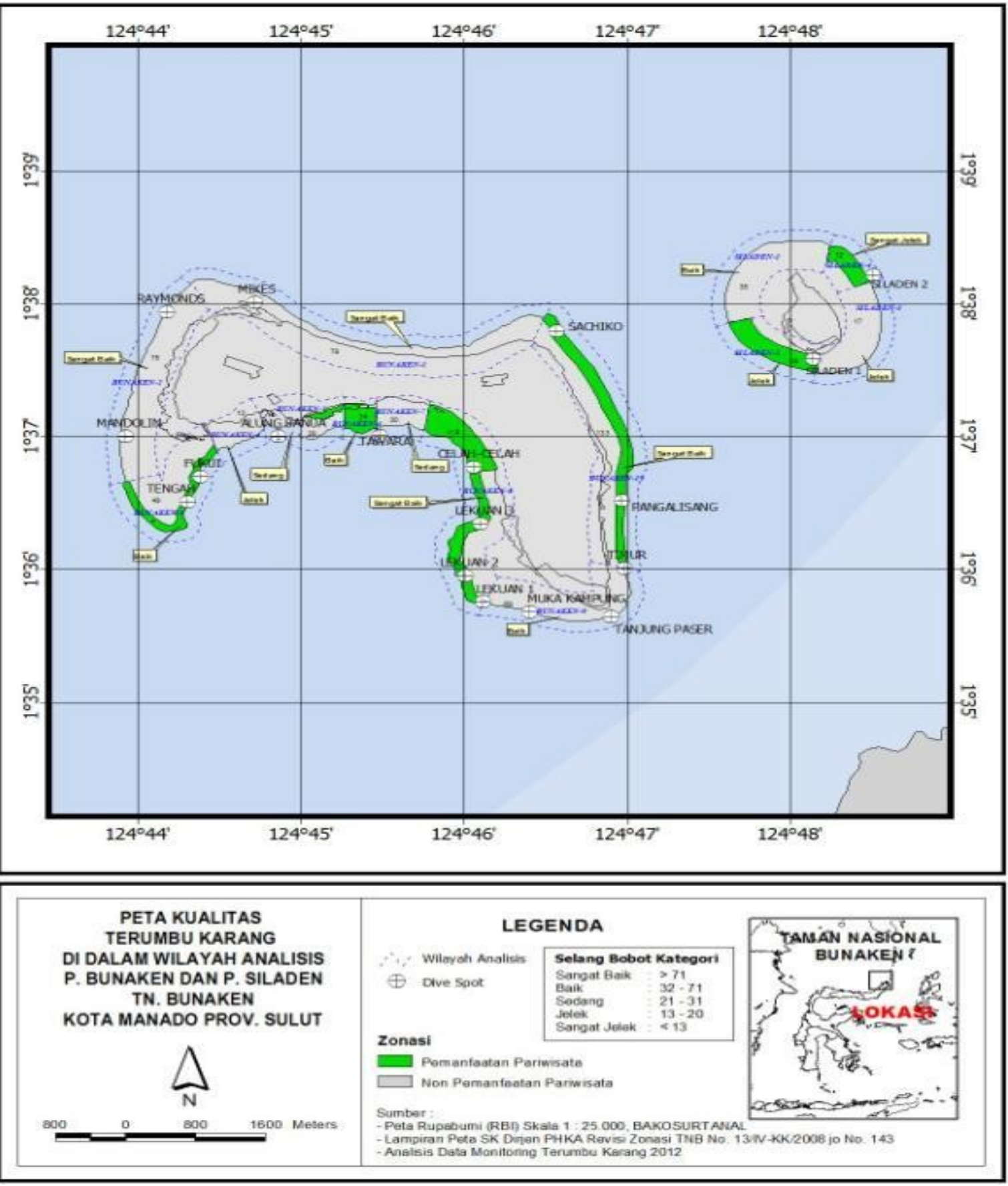

Gambar 1. Peta kategori karang Pulau Bunaken dan Siladen Berdasarkan hasil survey Manta Tow

MONITORING DAN EVALUASI LOKASI PENYELAMAN PULAU BUNAKEN 
Titik penyelaman Muka Kampung memiliki karakteristik bawah air berupa lereng yang curam dengan celah dan gua kecil, sering terdapat arus yang kuat serta puncak terumbu bervariasi. Kehidupan bawah air yang terdapat di dalamnya berupa keragaman karang, spons dan ikannya tinggi. Banyak ikan pemakan plankton seperti lolosi, ikan kupu-kupu, banner fishes, dan damselfishes, goropa dan gorara malam, serta memiliki avertebrata berupa spons tabung raksasa, gorgonian, whip corals, dan ascidia. Peluang menarik yang dapat dijumpai berupa penyu hijau, ular laut, hiu ekor putih, pari burung, ikan emperor besar, bobara, dan juga terdapat kuda laut kate.

Titik penyelaman Tawar memiliki memiliki karakteristik bawah air berupa tubir vertikal, puncak terumbu terbuka terhadap ombak. Kehidupan bawah air yang terdapat di dalamnya berupa ikan dokter, ikan behang dan ikan kakak tua, serta memiliki avertebrata berupa spong tabung, karang hitam, gorgonia besar, dan ascidians. Peluang menarik yang dapat dijumpai adalah bobara besar dan ikan pelagis lainnya.

Titik penyelaman Saciko memiliki karakteristik bawah air berupa tubir vertikal dengan goa karang pada kedalaman, sangat terbuka terhadap ombak, terdapat karangkarang masif besar pada bagian atas terumbu. Kehidupan bawah air yang terdapat di dalamnya berupa ikan pemakan planton, lolosi, ikan kupu-kupu, ikan keling, ikan pelatuk gigi merah, dan ikan pari besar, serta ikan kaca pada goa-goa besar, serta memiliki avertebrata berupa karang hitam, gorgonians besar, dan ascidians. Peluang menarik yang dapat dijumpai adalah penyu hijau, barakuda, ular laut, ikan komet, hiu ekor putih, pari burung, ribbon sweetlips, ikan emperors besar, dan bobara. Jika beruntung dapat terlihat hiu paus.

Titik penyelaman Tengah memiliki karakteristik bawah air berupa dinding lereng curam, sering terdapat arus yang kuat, puncak terumbu bervariasi, serta keragaman karang spons dan ikan tinggi. Kehidupan air yang terdapat di dalamnya berupa ikan pemakan planton, Iolosi, ikan kupu-kupu, bannerfishes, damselfishes, kerapu dan gorango malam, serta memiliki avertebrata berupa gorgonians, spons, nudibracia, dan ascidians.

Titik penyelaman Pangalisang memiliki karakteristik bawah air berupa tubir vertikal dengan banyak celah dan gua kecil. Memiliki kehidupan bawah air berupa ikan kupu-kupu, ikan dokter, ikan kakak tua dan ikan maming, serta memiliki avertebrata berupa banyak karang lunak, karang hitam, gorgonia dan ascidians. Peluang menarik yang dapat dijumpai adalah penyu, hiu ekor putih dan pari.

\section{KESIMPULAN}

Secara umum kondisi lokasi penyelaman di Pulau Bunaken masih dalam kategori baik, akan tetapi terdapat indikator menurunnya kualitas terumbu karang dari tahun ke tahun serta meningkatnya sampah yang masuk ke perairan Pulau Bunaken. Saran dari penelitian ini adalah perlu penelitian lanjutan tentang kondisi terumbu karang secara berkala untuk melihat laju degradasi terumbu karang serta penelitian tentang pencemaran lingkungan perairan di Pulau Bunaken.

\section{DAFTAR PUSTAKA}

Ceballos-Lascurain, H. 1996. Tourism, Ecotourism, and Protected Area. Gland, Switzerland: IUCN.

Damanik,J\& Weber, H.F. 2006. Perencanaan Ekowisata Dari Teori Ke Aplikasi. CV. Andi Offset. Yogyakarta.

Daniel, T.C. dan Booster, R.S. 1976. Measuring Landscape Esthetics: The Scenic Beauty Estimation Method. USDA Forest Service Research Paper. RM-167 Rocky Mountain Forest And Range Experiment Station Forest Service. US. Department of Agriculture.

Eplerwood, M. 1999. Successful Ecotourism Business. The Right Approach. Word

Ecotourism Conference, Kinabulu City.Sabah. 
Gomez, E.D. and H.T. Yap, 1988. Monitoring reef condition In : R.A.Kenchington \& B.E.T. Hudson (eds). Coral Reef Managementhandbook, UNESCO Jakarta : 187-195.

Haget S, 2009. Barriers For Tourism Sustainability In Destination. M.A

European Tourism Management Bournemouth University Universidad Rey Juan-Carlos, Madrid.

Halford, A.R dan Thompson A.A, 1994. Visual Census Surveys Of Reef Fish. Long term Monitoring of the Great Barrier Reef. Standard Operational Procedure number 3. Australian Institute Of Marine Science. Townsville.

Hill. M.O. 1973. Diversity and Evenness: A Unifying Notation and Its Consequences.Ecology, Vol. 54, No. 2. (Mar., 1973), pp. 427-432.

Hudson, K \& lee, D. 2010. Biodiversity and tourism, a valueable relationship. Social Alternatives. Vol.29 no.3. Proquest Sociology.

Johan Yar. 2011. Pengembangna Wisata Bahari Dalam Pengelolaan Sumberdaya Pulau-pulau Kecil Berbasis Ekologi. Studi Kasus Pulau Sebesi Provinsi Lampung. Sekolah Pascasarjana Institut Pertanian Bogor.

Kementerian Pariwisata dan Ekonomi Kreatif, 2013. Modul Pengembangan Community Based Eco Tourism (CBET) kawasan BIMP EAGA.

Keputusan Menteri Negara Lingkungan Hidup: KEP - 04/MENLH/02/2001 Tentang Kriteria Baku Kerusakan Terumbu Karang

Marpaung,H. $2002 . \quad$ Pengetahuan Kepariwisataan. Penerbit Alfabeta. Bandung.

Mehta A. 1999. Buku Panduan Lapangan Taman Nasional Bunaken. National park Natural History Book. NRM/EPIQ Program.Dinatu oleh yayaan Kelola Manado.
Mill, R.E. 1990. Tourism. The International Business.Prentice Hall Inc.Terjemahan Indonesia (2000) oleh PT Raja Grafindo Persada.

Nugroho, I. 2004. Buku Ajar Ecoturism. Program Studi Agribisnis, Fakultas Pertanian, Universitas Widyagama Malang.

Peraturan Menteri kebudayaan Dan Pariwisata, No. KM.67 / UM.001 /MKP/ 2004 Tentang pedoman Umum Pegembangan Pariwisata Di Pulaupulau Kecil

The International Ecotourism Society, 1991. TIES Global Ecotourism Fact Sheet. UNEP Tourism.www.unep.org.

Tuwo, H.A. 2011. Pengelolaan Ekowisata Pesisir dan laut.Pendekatan ekologi, sosial ekonomi, kelembagaan dan sarana wilayah.Penerbit Brilian Internasional. Jawa Timur. Indonesia.

UNEP \& UNWTO, 2005, Making Tourism More Sustainable - A Guide for Policy Makers.

UNEP. 1993. Monitoring Coral Reefs for Global Change : Reference Methods For Marine Pollution Studies No. 61. Program, Activity for Oceans and Coastal Areas. United Nations Environment rogram. Nairobi. pp25 39.

UWTO, 2011. Unwto annual report, a year of recovery. United Nation world tourism organization.

Western David, 1993. Memberi batasan tentang ekoturisme. Dalam Ekoturisme: petunjuk untuk perencana dan pengelola. Penyunting: Lindberg K. dan Hawkins, D.E. The Ecotourism Society. North Bennington. Vermont. Terjemahan Bahasa Indonesia kerjasama Private Agencies Collaborating Together (PACT) dan Yayasan Alam Mitra Indonesia (ALAMI). 